\title{
The learning officer decision matrix - a structural equation modeling approach for the management of asynchronous e-Learning projects
}

\author{
Nuno Pena, UnYLeYa Portugal and ISEG - School of Economics and Management, \\ University of Lisbon, Portugal, npena@unyleya.com
}

\begin{abstract}
Effectiveness is one of the major concerns in corporate e-Learning and is critical when projects face financial and time-to-market constraints. Organizations and corporate universities seek methodologies and tools to help them manage more efficiently diverse e-Learning Projects. This paper describes the outcome of a case study on the assessment of the effectiveness of an $e$ Learning project $(n=1317)$, from sixteen different corporations in the context of insurance and banking industry in Portugal. Results will be presented on the application of the methodology proposed by Levy for the assessment of the effectiveness of e-Learning systems. Based on the output of this assessment, this paper will present a new tool, the Learning Officer Decision Matrix, which will contribute to a more efficient management of corporate e-Learning projects.
\end{abstract}

Keywords: e-Learning, effectiveness, quality, asynchronous, Partial Least Squares.

\section{Introduction}

The concept of e-Learning is subject to constant change. An inclusive definition describes $e$ Learning as "an approach to teaching and learning, representing all or part of the educational model applied, that is based on the use of electronic media and devices as tools for improving access to training, communication and interaction and that facilitate the adoption of new ways of understanding and developing learning" (Sangrà, Vlachopoulos, \& Cabrera, 2012).

In order to better delimit this wide-ranging concept, Negash and Wilcox (2008) proposed six types of e-Learning classifications: (1) e-Learning with physical presence and without ecommunication (face-to-face), (2) e-Learning without presence and without e-communication (self-learning), (3) e- Learning without presence and with e-communication (asynchronous), (4) e-Learning with virtual presence and with e-communication (synchronous), (5) e-Learning with occasional presence and with e-communication (blended/hybrid-asynchronous), and (6) eLearning with presence and with e-communication (blended/hybrid-synchronous).

E-Learning classifications can aid researchers in identifying learning effectiveness for specific formats and how it alters the student learning experience. In this paper the e-Learning classification used blends self-learning content (type 2), asynchronous communication with tutors and peers (type 3) and a face-to-face final examination (type 5). Throughout the paper, this typology will be generally nominated as 'asynchronous e-Learning'. 


\section{Purpose of the Study and methodology}

The main objectives of this paper are (1) to assess the effectiveness of an e-Learning project, more specifically, an asynchronous e-Learning project, (2) to determine and manage quality improvement measures of an asynchronous e-Learning project, and (3) based on the output of the previously stated objectives, to conceive a managerial instrument, a highly practical and accurate tool that can contribute to a more efficient management of corporate e-Learning projects. Consistent with its objectives, this paper is organized in the following manner. First, a case study on the assessment of the effectiveness of an e-Learning project $(n=1317)$, from 16 different corporations in the context of insurance and banking industry in Portugal will be presented. Secondly, the results from this assessment of effectiveness, through the use of an online questionnaire, will be presented and analyzed based on the application of the methodology proposed by Levy (missing year of publication) for the assessment of the effectiveness of eLearning systems. Since the original model was adapted for asynchronous e-Learning, a new model was restructured based on three dimensions and 41 characteristics. Next, in order to test this new model, author resorted firstly to exploratory factor analysis through Principle Component Analysis (PCA) and subsequent to the structured equation model (Partial Least Squares methodology). Finally, based on the output of these methodologic procedures, a new tool was conceived, a Learning Officer Decision Matrix, which will contribute to a more efficient management of corporate e-Learning Projects. The conclusions and recommendations round out the paper.

\section{Assessment of effectiveness}

An e-Learning project (Insurance Broker Training Program Certifications - General, Life, Nonlife and Reinsurance) was developed based on IPTEACES e-Learning framework (Pena, \& Isaias, 2012; 2013). IPTEACES (acronym for Involvement, Preparation, Transmission, Exemplification, Application, Connection, Evaluation and Simulation) is an e-Learning Framework conceived to facilitate e-Learning by reducing diversity in programs facing a nonhomogeneous audience. This instructional design framework was primarily developed through a pedagogical benchmark, mainly the Nine Events of Instruction (Gagne, Briggs, \& Wager, 1992), Merrill (2002; 2007)'s Principles of Learning, Keller (2008)'s ARCS's model, and van Merrienboer's et al (2005), Ten Steps to Complex Learning (van Merriënboer \& Kirschner, 2012), the investigating award winning e-courses (e.g. Brandon Hall Excellence in Learning Awards, International eLearning Association Awards), and Bersin \& Associates' corporate ELearning best practices.

This e-Learning Project (Insurance Broker Training Program Certifications - General, Life, Nonlife and Reinsurance), targeting 3,726 employees from sixteen different corporations associated with insurance and banking industry in Portugal, accomplished results that fulfill the traditional main objectives of pedagogical efficacy: high approval rate, low dropout rate and high level of satisfaction from the students. This presents a brief characterization of student's demographic indicators as well as a brief characterization of the success indicators: 
Table 1: Characterization of student's demographic indicators

\begin{tabular}{|l|l|}
\hline Industry: & $\begin{array}{l}1,614 \text { learners }(43,3 \%) \text { came from the insurance industry and } \\
2112 \text { learners }(56,7 \%) \text { from the banking industry. }\end{array}$ \\
\hline Gender: & $\begin{array}{l}\text { Average of } 34 \text { years old, with a standard deviation of } 8.8 \text { years. } \\
\text { Learners range from } 18 \text { years old to } 71 \text { years old. The } \\
\text { distribution was higher in the age category between '24 and 34' } \\
\text { years old. }\end{array}$ \\
\hline $\begin{array}{l}\text { Academic } \\
\text { Qualifications: }\end{array}$ & $\begin{array}{l}\text { Secondary education } 1,607 \text { (43,1\%); Undergraduate degree } \\
1,447(38,8 \%) \text { and } 522 \text { with Primary Education (14,0\%). }\end{array}$ \\
\hline Residency: & $\begin{array}{l}\text { Residence shows a high variability; learners came from } 18 \\
\text { regions of the Portuguese territory (majority of main cities) }\end{array}$ \\
\hline
\end{tabular}

Among the 3,726 learners who attended the Insurance Broker Training Program certifications ecourses, 3,542 passed the course (approbation rate of 95.0\%), and 184 failed (failure rate of $4.9 \%)$. More precisely, concerning the three exam sessions, 3,100 learners $(83,2 \%)$ were approved the first time they took the exam, 382 learners were approved on the second exam session $(10,2 \%)$, and finally 60 learners on the third exam session $(1,6 \%)$. The global average score of the learners was $82.5 \%$, with a standard deviation of 11.0.

Among the 3,526 learners, 1,770 learners answered the survey of evaluation of satisfaction, obtaining a response rate of $50.2 \%$. The analysis of the answers showed that, generally, the learners were satisfied or very satisfied with the courses, ranking their answers over 3 on a 4 point Likert scale. An overwhelming majority (76.9\%) of the students did not have a previous eLearning experience in a professional context.

This project produced results that are considered to fulfill the traditional main pedagogical objectives of a corporate e-Learning project. In the quest for effectiveness, the author searched to identify an international benchmark that could help identify the actual effectiveness of this eLearning project and fundamentally to help recognize items for quality improvement. In the context of the assessment of e-Learning System's effectiveness, Levy (2006) as well as Levy, Murph, \& Zanakisy 2009) developed an investigation by querying students concerning the characteristics of e-Learning systems that they value and consider important during their learning experience. This author states that it is not the number of satisfied students or the level of satisfaction that suggest the system's effectiveness - it is the extent in which students are more satisfied with the system performance with what they perceive as important.

Levy (2006) as well as Levy et al. (2009) proposed a set of characteristics that learners found important, or value, when using e-Learning systems. The list of e-Learning system characteristics was built primarily from an exhaustive review of literature and subsequently through exploratory focus groups, as well as in a qualitative questionnaire. Levy (2006) developed an assessment of such characteristics using a survey instrument. The proposed survey 
instrument item scales ranged from (1) very unsatisfied to (6), extremely satisfied and (1) not important to (6) extremely important. Levy proposed 48 e-Learning System characteristics, grouped according to the four dimensions proposed by Webster and Hackley (1997)'s technology and support (14 characteristics), course (12 characteristics), professor (7 characteristics), and learner's dimension (15 characteristics).

In order to determine the level of effectiveness of the Insurance Broker Training e-Learning project, the author applied Levy's proposed methodology. Due to the specificity of this eLearning project (asynchronous e-Learning), the Professor dimension was withdrawn (therefore seven characteristics directly linked with this dimension), leaving three dimensions and respectively 41 system characteristics - Dimension A "Technology and Support; Dimension B "Course" and Dimension D "Student" - ( cf. Appendix A).

Levy (2006) as well as Levy et al. (2009) proposed two benchmark tools based on the outputs of the questionnaire that can be complemented: "the Value-Satisfaction grid" and "LeVIS index". The objective of "Value-Satisfaction grid" is to provide an indication of action and improvement priorities for the e-Learning system dimension and the e-Learning system characteristics. The "Value-Satisfaction grid" was based on aggregated student perceived satisfaction as well as aggregated student-perceived value of e-Learning system characteristics. In this study the measures scale ranges from 1 to 6 , while no scores were noted below 3 in satisfaction and below 3 in value, resulting in the use of 4.5 as the cutoff point between low and high on both axes of the grid.

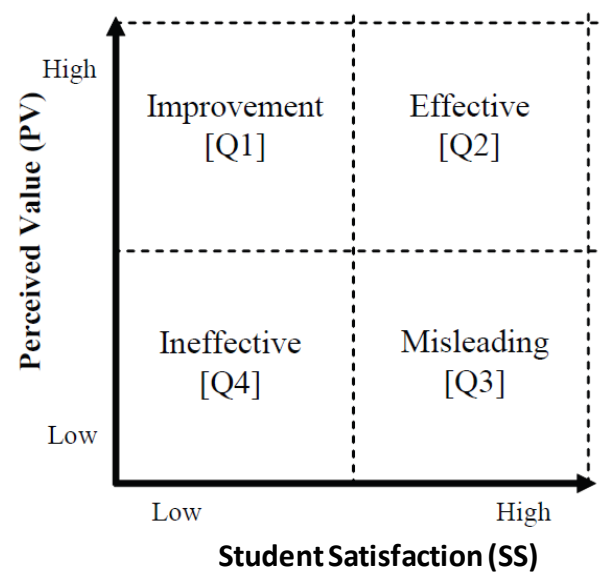

Figure 1: The Value-Satisfaction grid (Levy, 2006; Levy et al., 2009)

The "Value-Satisfaction grid" does not provide however a measure of the magnitude of eLearning system effectiveness and therefore should be complemented with another tool. The "LeVIS index" proposed by Levy (2006) provides that measure as an overall index of learners' perceived effectiveness of e-Learning systems by combining e-Learning system value measures and e-Learning systems satisfaction measures. "LeVIS index" is proposed as a benchmarking tool combining the learners' perceived value and satisfaction in order to indicate learners' perceived e-Learning system's effectiveness. 
The "Value-Satisfaction grid" suggests that it is not sufficient that only value or only satisfaction measures are high, rather the combination of both value and satisfaction. Consequently, the "LeVIS index" was proposed by Levy as the multiplication of the overall satisfaction $\left(\mathrm{S}^{\circ}\right)$ by the overall value $\left(\mathrm{V}^{\circ}\right)$. "LeVIS index" provides a score of the overall magnitude of the effectiveness of the e-Learning system under study. The magnitude of LeVIS provides that when LeVIS is near 0 , this indicates very low learners' perceived e-Learning system's effectiveness. When LeVIS is near 1, this indicates very high learners' perceived e-Learning system's effectiveness. This measure provides that if only one of the two measures $(\mathrm{S} \circ$ or $\mathrm{V} \circ$ ) is high, the overall system measure (LeVIS) score is not high. As noted by Levy, an observed limitation of LeVIS is due to the equal importance given for value and satisfaction.

\section{Assessing the effectiveness of the Insurance Broker e-Learning Project}

Due to corporate policies and constraints, the application of the adapted version of the online questionnaire targeted only 2,531 students of the original 3,726 students. The response rate was $52.03 \%$, i.e., 1,317 trainees. More specifically, 59.6\% of respondents were from the banking industry, $40.4 \%$ were from the insurance industry.Results from Overall Value-Satisfaction Grid are presented below:

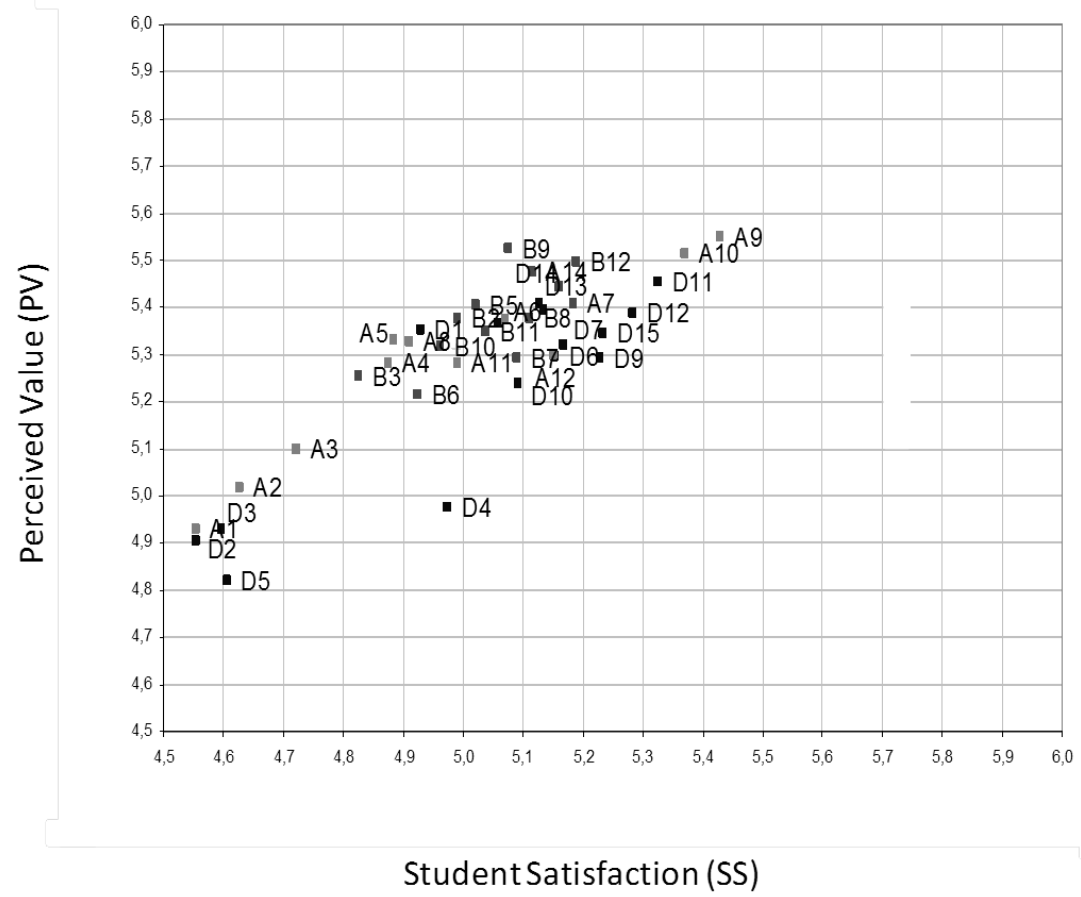

Figure 2 - Overall Value-Satisfaction Grid (all dimensions)

The Overall Value-Satisfaction Grid shows that all the 41 e-Learning system characteristics are situated in the in the 'Effective Quadrant'. All the characteristics and dimensions are considered effective. Having 'excellence' as orientation, as it can be seen in this overall grid, there are seven e-Learning System Characteristics that are somehow separate from the other 34 (less effective). 
These seven e-Learning system characteristics positioned on the lower corner of the quadrant somehow represent that there are two groups (or sub-categories) that should be considered to have priority in terms of quality improvement: HelpDesk (A1, A2 and A3) originally corresponding to "Dimension A - Technology and Support" and Class (D3, D2, D4 and D5) originally corresponding to "Dimension D - Learner" - (cf. Appendix A).

Results from the Global LeVIS index indicate (see Figure 3) that the overall e-Learning system under study reached a global LeVIS score of 0.781 and therefore should be classified as "High Effectiveness". All the dimensions are above 0.75 global scores and therefore can be considered as having High Effectiveness, (Dimension A - 0.757; Dimension B - 0.767, Dimension D 0.758), with a particular emphasis on Dimension $B-$ Course which had the highest score of all dimensions.

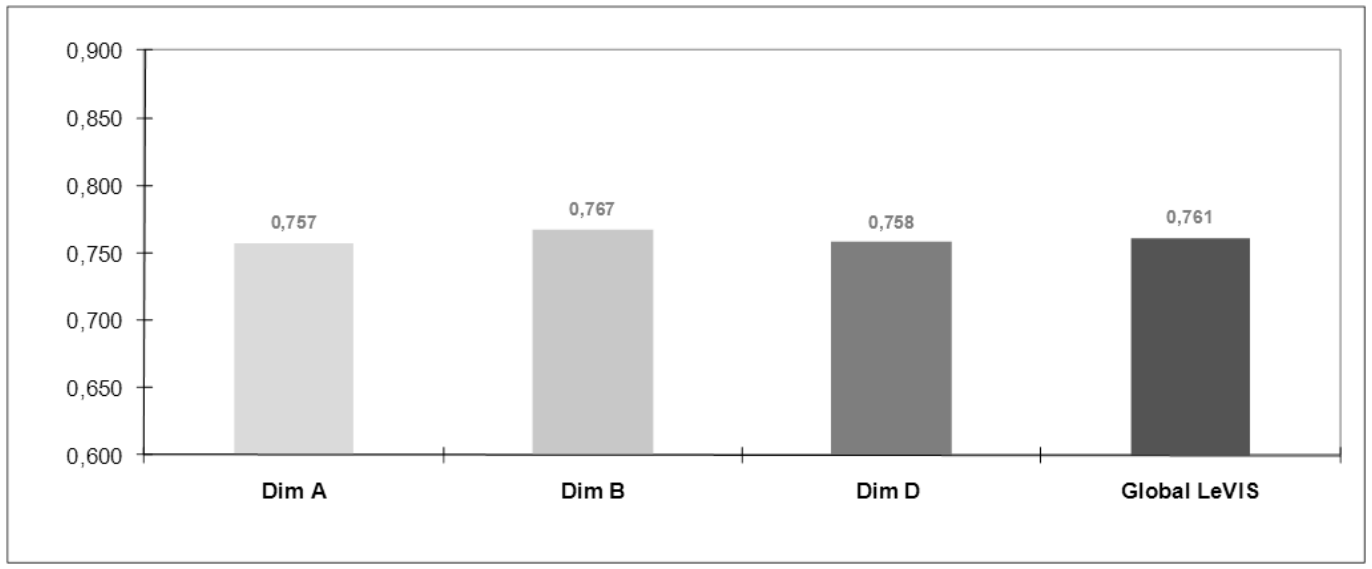

Figure 3 - LeVIS index (all dimensions)

\section{Testing the adapted Model}

Based on the outputs of Overall Value-Satisfaction Grid, the author felt the need to review the new model based on three dimensions (adapted for asynchronous e-Learning) and to reanalyze their correspondent attributes (41 characteristics). In order to design and test the new model, the author used firstly exploratory factor analysis through Principle Component Analysis and subsequently structured equation model (Partial Least Squares methodology).

To perform the Exploratory Factor Analysis the author resorted to Principle Component Analysis (PCA) - $(\mathrm{n}=1317)$ with Varimax Rotation and Kaiser Normalization.

Table 2: Bartlett's sphericity test and Kaiser-Meyer-Olkin measure of sampling adequacy

\begin{tabular}{|l|l|l|}
\hline \multicolumn{2}{|l|}{ Kaiser-Meyer-Olkin measure of sampling adequacy. } & .980 \\
\hline Bartlett's test of sphericity & Chi - Square & 32250,824 \\
\cline { 2 - 3 } & Degrees of Freedom & 820 \\
\cline { 2 - 3 } & Evidential value & .000 \\
\hline
\end{tabular}


Table 3, below, presents commonalities and the total explained variance.

Table 3: Presentation of Factors - Rotation Method: Varimax with Kaiser Normalization.

\begin{tabular}{|l|r|l|r|l|r|l|r|l|r|r|r|}
\hline & Extraction & & Extraction & & Extraction & & Extraction & Extraction & Extraction \\
\hline B1 &, 797 & B8 &, 796 & A5 &, 667 & A12 &, 754 & D10 &, 707 & D3 &, 912 \\
\hline B2 &, 824 & B9 &, 819 & A6 &, 720 & A13 &, 762 & D11 &, 726 & D4 &, 873 \\
\hline B3 &, 789 & B10 &, 817 & A7 &, 725 & A14 &, 689 & D12 &, 794 & D5 &, 866 \\
\hline B4 &, 780 & B11 &, 828 & A8 &, 699 & D6 &, 775 & D13 &, 733 & A1 &, 862 \\
\hline B5 &, 816 & B12 &, 730 & A9 &, 802 & D7 &, 780 & D14 &, 797 & A2 &, 871 \\
\hline B6 &, 790 & D1 &, 742 & A10 &, 826 & D8 &, 722 & D15 &, 719 & A3 &, 824 \\
\hline B7 &, 839 & A4 &, 700 & A11 &, 752 & D9 &, 682 & D2 &, 908 & & \\
\hline
\end{tabular}

The saturations of the variables in each factor have been always above the required minimum of $40 \%$, which is confirmed by the following structure of five factors:

- Factor 1 - Course Contents: This factor is related to the availability and quality of the content of the course and includes 13 items $(\alpha=0.977)$;

- Factor 2 - Accessibility / Asynchronous: This factor includes 11 items related to accessibility and operability of access to the course $(\alpha=0.957)$. The variable A4 (System operation time (up-time)), included in this factor, is slightly more associated with Factor 5 , however, due to the similarity of values and theoretical relevance, the author chooses to keep this variable associated factor 2.

- Factor 3 - Perceived Value: The third factor includes 10 items $(\alpha=0.959)$, which are related to perceived value in the possibility of reconciling the course with daily and professional activities as well as extra-professional activities.

- Factor 4 - Class: The class factor includes four items related to peer interaction in training $(\alpha=0.962)$.

- Factor 5 - Helpdesk: This factor includes three items of response, related to quality and support provided by the helpdesk $(\alpha=0.939)$.

- Grouping Factor - There is, therefore, an appropriate grouping factor. The internal consistency analysis produced results that allow verifying the suitability of the factors identified. The Cronbach's alpha $(\alpha)$ had values well above 0.7, which indicate a high internal consistency. In factor 2 , the Cronbach's alpha $(\alpha)$ of 0.957 also allows supporting the decision to keep the item "A4" associated with this factor, since its elimination would result in a lower level of consistency factor (0.957 to 0.954$)$.

\section{Structural Equation Modeling}

In a second stage, in order to test the relationship between the five identified factors - Course Content, Accessibility / Asynchronous, Perceived Value, Class and Helpdesk - and the central 
variable in the study - Global LeVIS - the author resorted to Structural Equation Model, more specifically, to Partial Least Squares (PLS) methodology. "Educational researchers frequently work in a situation with massive amounts of data, but the relative scarcity of theoretical knowledge. In such a problem area, partial least squares (PLS) path analysis with latent constructs is a useful and flexible tool for statistical model building. The use of PLS may be considered especially when the research situation at hand demands the investigation of complex models in an exploratory rather than a confirmatory fashion" (Sellim, 1995).

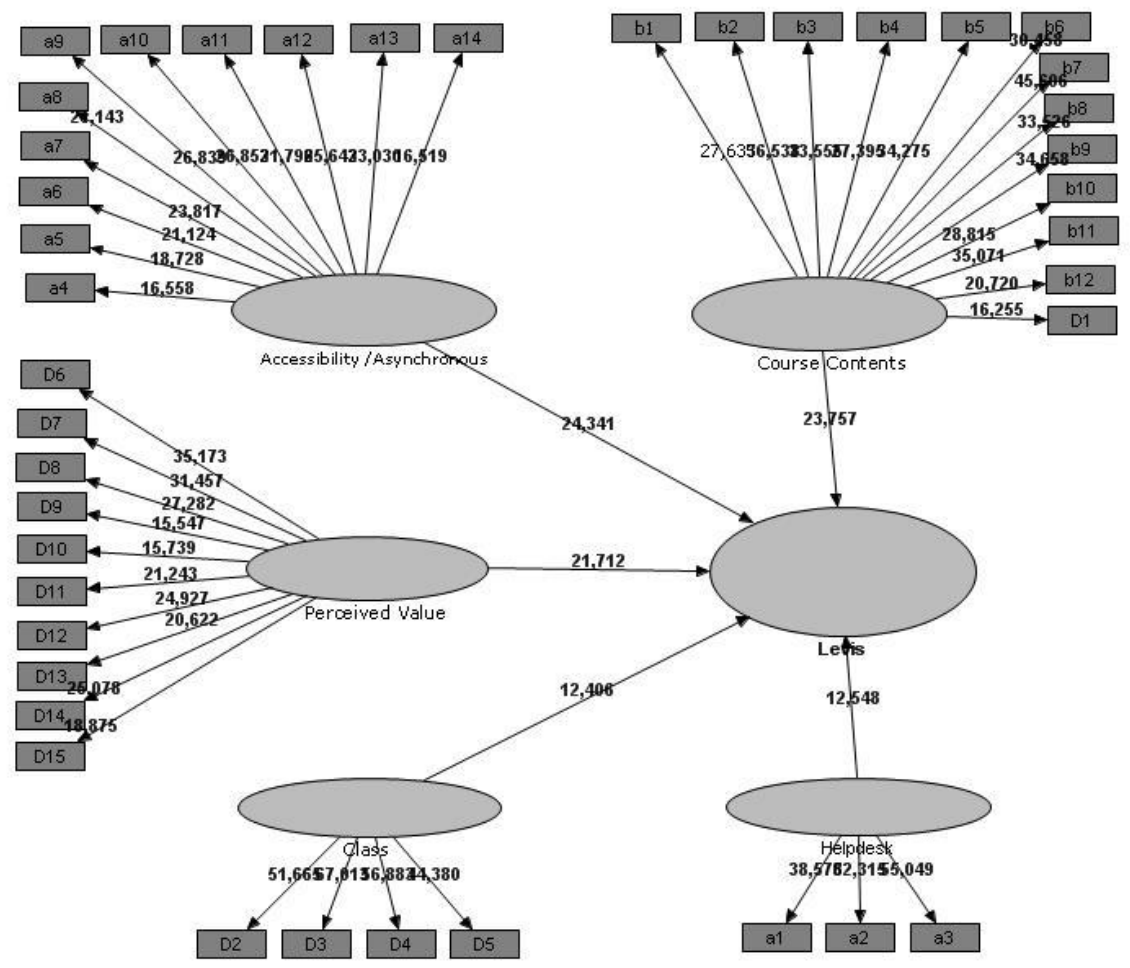

Figure 4: Partial Least Squares - Values of T for the correlations

Table 4: Synthesis of Global data model quality (PLS)

\begin{tabular}{|l|c|c|c|c|c|}
\hline & $\begin{array}{c}\text { Average } \\
\text { variance } \\
\text { extracted }\end{array}$ & $\begin{array}{c}\text { Composite } \\
\text { Reliability }\end{array}$ & $\begin{array}{c}\text { Cronbach's } \\
\text { Alpha }\end{array}$ & Commonality & Redundancy \\
\hline Levis & 0,5938 & 0,9835 & 0,9826 & 0,5938 & 0,2527 \\
\hline $\begin{array}{l}\text { Accessibility } \\
\text { /Asynchronous }\end{array}$ & 0,6868 & 0,9602 & 0,9543 & 0,6868 & 0,0000 \\
\hline Course Contents & 0,7681 & 0,9773 & 0,9747 & 0,7681 & 0,0000 \\
\hline Helpdesk & 0,8856 & 0,9587 & 0,9355 & 0,8856 & 0,0000 \\
\hline Class & 0,9003 & 0,9731 & 0,9631 & 0,9003 & 0,0000 \\
\hline Perceived Value & 0,7166 & 0,9619 & 0,9559 & 0,7166 & 0,0000 \\
\hline
\end{tabular}


The average extracted variance for each factor exceeds the minimum required value of 0.50 (Fornell \& Bookstein, 1981). In this case, all values from the Internal Consistency Composite exceed 0.96. The model based on five proposed factors - Course Content, Accessibility / Asynchronous, Perceived Value, Class and Helpdesk - was totally confirmed. Appendix B presents detailed results from the PLS model.

\section{Chief Learning Officers' Decision Matrix}

In the quest for "excellence" and in order to support a systematic program of actions to be implemented in line with a continuous quality improvement, the author performed the identification of indicators, which represent priorities' to act on. In order to conceive a new tool which could contribute to a more efficient management of corporate e-Learning Projects, author developed the "Learning Officer Decision Matrix" (LODM). LODM has as input the data produced by LeVIS index as well as the data resulting from Partial Least Squares, based on the new model of three dimensions and their correspondent attributes (specially adapted for asynchronous e-Learning).

Below are descriptions of concepts used in the following tables:

Concepts:

- Factors Standardized Weights - standardized output of PLS Path Coefficients, specifically "Original Sample";

- Items Standardized Weights - standardized output of PLS Outer Weights;

- LeVIS - Score from students (Standardized (satisfy * important));

- Excellence = 1 (i.e., $100 \%$ );

- Market Deviation = Excellence - LeVIS score;

- $\quad$ Competitive Deviation = Market Deviation * Standardized Weights;

- $\quad$ Effort = Standardized Competitive Deviation;

- $\quad$ Priorities = Ranking of Effort.

Based on the outputs resultant from Structural Equation Modeling through PLS, table 5 below presents the ranking of the five dimensions priorities for quality improvement intervention, i.e., the factors (dimensions) which can contribute more to raise Global LeVIS score.

Table 5 - Dimension improvement ranking

\begin{tabular}{|l|r|r|r|r|r|r|r|}
\hline \multicolumn{1}{|c|}{ Factors } & $\begin{array}{c}\text { Standardize } \\
\text { d Weight }\end{array}$ & LeVIS & Excellence & $\begin{array}{c}\text { Market } \\
\text { Deviation }\end{array}$ & $\begin{array}{c}\text { Competitive } \\
\text { Deviation }\end{array}$ & Effort & Priorities \\
\hline F1 - Course Contents & $35 \%$ & 0,728799 & 1 & 0,271201000 & 0,081540929 & $30 \%$ & 1 \\
\hline F2 - Accessibility /Asynchronous & $25 \%$ & 0,752995 & 1 & 0,247005167 & 0,061692537 & $23 \%$ & 2 \\
\hline F3 - Perceived Value & $24 \%$ & 0,778063 & 1 & 0,221936535 & 0,054692257 & $20 \%$ & 3 \\
\hline F4 - Class & $10 \%$ & 0,654201 & 1 & 0,345798722 & 0,043265968 & $16 \%$ & 4 \\
\hline F5 -Helpdesk & $7 \%$ & 0,643885 & 1 & 0,356114887 & 0,027784416 & $10 \%$ & 5 \\
\hline
\end{tabular}


The factor 1 - "Course Contents" emerges as the first priority factor for action improvement, which should be invested an effort of $35 \%$ to improve effectiveness, i.e., to improve Global LevIS. The second factor "Accessibility / Asynchronous" emerges as second priority to invest, where the effort should be about 25\%, while the third factor "Perceived Value" is the third priority of intervention that requires an effort of $24 \%$. Factors "Class" and "Helpdesk" are the 4 th and 5th priority, which should focus respectively $10 \%$ and $7 \%$ of intervention efforts at the level of measures to improve global LeVIS.

As the next step and in order to identify more detail priorities for action improvement, specifically with regard to each item (characteristic) belonging to each factor (dimension), the author performed the analysis of the priorities of every single indicator/characteristic (cf. Appendix A).

Data presented in Table 6 reveals that the first priorities for action improvement relate to the three items linked to "class", in which item D5 "Being part of a 'class' although it was online" should be the first priority intervention, representing $3.53 \%$ of the improvement efforts. D2 "Amount of interaction with classmates" and D3 -" Quality of interaction with classmates ", appear as the second and third priority, requiring respectively $3.39 \%$ and $3.33 \%$ of the intervention efforts.

Data also shows that item A1 - "Quick answer from technical support (HelpDesk) via phone", performance-related to the helpdesk, is the fourth priority for action, representing an effort of 3.19\%. After the fifth priority item D4 - "Classmates' attitude (across all courses)" which is again related to Class Dimension, requires $3.17 \%$ of intervention efforts of improvement actions. Subsequently, items A2 - " Quick answer from technical support (Help Desk) after-hours via email" and A3 " Quality of technical support (Help Desk)", again related to the Helpdesk Dimension, represent, respectively the 6th and 7th priority, which should be invested $3.17 \%$ and $3.10 \%$ of the effort.

One possible reason for the improvement of these items related to "Class" is that, despite being an asynchronous e-Learning project, the use of the asynchronous collaboration tools (especially non moderated peer discussion forums) were throughout the course voluntary and nonmandatory - therefore these tools were insufficiently promoted and a significant amount of students did not use them or eventually had difficulties in their use. In this sense, it should be developed strategies to promote even more peer communication (students-students) and produced different mechanisms that can facilitate students to use these e-Learning tools. In terms of items concerning Dimension "HelpDesk", it should be implemented a strategy in order to gain a superior level of satisfaction from the students concerning HelpDesk services by increasing, for example, the Helpdesk SLA's (service level agreements). Items B6 - "Availability of other content (syllabus, objectives, assignments, schedule)", and B3 - "Amount of material in courses" 
and B10 - "Gathering information quickly" are respectively the 8th, 9th and 10th priorities where intervention efforts should be $3.05 \%, 2.94 \%$ and $2.77 \%$ respectively.

Table 6 - Improvement ranking for all items

\begin{tabular}{|c|c|c|c|c|c|c|c|}
\hline Itens & $\begin{array}{c}\text { Standardized } \\
\text { Weight }\end{array}$ & LeVIS & Excellence & $\begin{array}{c}\text { Market } \\
\text { Deviation }\end{array}$ & $\begin{array}{c}\text { Competitive } \\
\text { Deviation }\end{array}$ & Effort & Priorities \\
\hline a3 & $2,4 \%$ & 0,679870075 & 1 & 0,32012992 & 0,007731562 & $3,10 \%$ & 7 \\
\hline $\mathrm{a} 2$ & $2,3 \%$ & 0,6558888805 & 1 & 0,3441112 & 0,007904686 & $3,17 \%$ & 6 \\
\hline a1 & $2,2 \%$ & 0,634480722 & 1 & 0,36551928 & 0,007960401 & $3,19 \%$ & 4 \\
\hline d5 & $2,4 \%$ & 0,636948452 & 1 & 0,36305155 & 0,008805863 & $3,53 \%$ & 1 \\
\hline $\mathrm{d} 4$ & $2,4 \%$ & 0,669640597 & 1 & 0,3303594 & 0,007905395 & $3,17 \%$ & 5 \\
\hline d3 & $2,4 \%$ & 0,648443432 & 1 & 0,35155657 & 0,008314113 & $3,33 \%$ & 3 \\
\hline d2 & $2,3 \%$ & 0,638994347 & 1 & 0,36100565 & 0,008465779 & $3,39 \%$ & 2 \\
\hline d7 & $2,6 \%$ & 0,777587952 & 1 & 0,22241205 & 0,005828688 & $2,33 \%$ & 25 \\
\hline $\mathrm{d} 8$ & $2,6 \%$ & 0,766156247 & 1 & 0,23384375 & 0,005972351 & $2,39 \%$ & 22 \\
\hline d6 & $2,6 \%$ & 0,771450266 & 1 & 0,22854973 & 0,006003390 & $2,40 \%$ & 20 \\
\hline $\mathrm{d} 10$ & $2,2 \%$ & 0,755800219 & 1 & 0,24419978 & 0,005393093 & $2,16 \%$ & 28 \\
\hline d 9 & $2,2 \%$ & 0,783746731 & 1 & 0,21625327 & 0,004710358 & $1,89 \%$ & 34 \\
\hline $\mathrm{d} 15$ & $2,3 \%$ & 0,791487387 & 1 & 0,20851261 & 0,004710279 & $1,89 \%$ & 35 \\
\hline $\mathrm{d} 13$ & $2,3 \%$ & 0,782270311 & 1 & 0,21772969 & 0,005028476 & $2,01 \%$ & 31 \\
\hline d11 & $2,3 \%$ & 0,820235383 & 1 & 0,17976462 & 0,004158936 & $1,67 \%$ & 39 \\
\hline $\mathrm{d} 12$ & $2,4 \%$ & 0,805323547 & 1 & 0,19467645 & 0,004692739 & $1,88 \%$ & 37 \\
\hline $\mathrm{d} 14$ & $2,4 \%$ & 0,783113980 & 1 & 0,216886020 & 0,005105402 & $2,04 \%$ & 30 \\
\hline a4 & $2,1 \%$ & 0,725491437 & 1 & 0,27450856 & 0,005883099 & $2,36 \%$ & 23 \\
\hline a5 & $2,2 \%$ & 0,732135324 & 1 & 0,26786468 & 0,005796017 & $2,32 \%$ & 26 \\
\hline$a 6$ & $2,3 \%$ & 0,767695942 & 1 & 0,23230406 & 0,005357509 & $2,15 \%$ & 29 \\
\hline a8 & $2,3 \%$ & 0,737323884 & 1 & 0,26267612 & 0,005998306 & $2,40 \%$ & 21 \\
\hline a11 & $2,4 \%$ & 0,745022357 & 1 & 0,25497764 & 0,006017294 & $2,41 \%$ & 19 \\
\hline a12 & $2,4 \%$ & 0,771408082 & 1 & 0,22859192 & 0,005517322 & $2,21 \%$ & 27 \\
\hline a14 & $2,2 \%$ & 0,787184679 & 1 & 0,21281532 & 0,004644413 & $1,86 \%$ & 38 \\
\hline a7 & $2,2 \%$ & 0,790074243 & 1 & 0,20992576 & 0,004694044 & $1,88 \%$ & 36 \\
\hline a13 & $2,3 \%$ & 0,790664811 & 1 & 0,20933519 & 0,004875333 & $1,95 \%$ & 33 \\
\hline a 9 & $2,2 \%$ & 0,847148401 & 1 & 0,1528516 & 0,003373655 & $1,35 \%$ & 41 \\
\hline $\mathrm{a} 10$ & $2,3 \%$ & 0,832784949 & 1 & 0,16721505 & 0,003811513 & $1,53 \%$ & 40 \\
\hline b1 & $2,7 \%$ & 0,747490087 & 1 & 0,25250991 & 0,006763633 & $2,71 \%$ & 11 \\
\hline b12 & $2,5 \%$ & 0,802602717 & 1 & 0,19739728 & 0,005022133 & $2,01 \%$ & 32 \\
\hline b9 & $2,8 \%$ & 0,756601704 & 1 & 0,2433983 & 0,006705421 & $2,69 \%$ & 13 \\
\hline d1 & $2,6 \%$ & 0,743693580 & 1 & 0,256306420 & 0,006716589 & $2,69 \%$ & 12 \\
\hline b8 & $2,7 \%$ & 0,775352232 & 1 & 0,22464777 & 0,006079080 & $2,43 \%$ & 18 \\
\hline b6 & $2,7 \%$ & 0,727094406 & 1 & 0,27290559 & 0,007351620 & $2,94 \%$ & 9 \\
\hline b3 & $2,7 \%$ & 0,716295453 & 1 & 0,28370455 & 0,007607865 & $3,05 \%$ & 8 \\
\hline b10 & $2,7 \%$ & 0,746098034 & 1 & 0,25390197 & 0,006917241 & $2,77 \%$ & 10 \\
\hline b4 & $2,6 \%$ & 0,774234371 & 1 & 0,22576563 & 0,005861095 & $2,35 \%$ & 24 \\
\hline b11 & $2,7 \%$ & 0,760672404 & 1 & 0,239327596 & 0,006542110 & $2,62 \%$ & 16 \\
\hline b5 & $2,7 \%$ & 0,764236902 & 1 & 0,235763098 & 0,006307859 & $2,53 \%$ & 17 \\
\hline b7 & $2,7 \%$ & 0,760503670 & 1 & 0,239496330 & 0,006583296 & $2,64 \%$ & 14 \\
\hline b2 & $2,7 \%$ & 0,755863494 & 1 & 0,244136506 & 0,006554259 & $2,63 \%$ & 15 \\
\hline
\end{tabular}

\section{Conclusion and Further Research Directions}

This paper described the outcome of a case study on the assessment of the effectiveness of an eLearning project $(n=1317)$, in the context of sixteen different corporations in the insurance and banking industry in Portugal. Based on the methodology proposed by Levy $(2006 ; 2009)$ for the assessment of the effectiveness of e-Learning systems, the author assessed the effectiveness of 
this e-Learning project. Results showed that the Global LeVIS of the e-Learning system under study reached a score of 0.781 and therefore should be classified as "highly effective". All of the 41 e-Learning system characteristics were situated in the in the 'Effective Quadrant'. In order to review the new model based on three dimensions (adapted for asynchronous e-Learning) and also to reanalyze their corresponding attributes, the author performed a firstly exploratory factor analysis through Principle Component Analysis and subsequently a structural equation model (Partial Least Squares methodology). Based on the output of these methodology procedures, the author developed a new tool, a Learning Officer Decision Matrix, which will contribute to a more efficient management of corporate e-Learning Projects. The Learning Officer Decision Matrix (LODM) produces practical and actionable information for decision making and gives metrics such as "priorities" and "effort" that are more understandable and pragmatic for managers. Managers can replicate the proposed procedure in order to gain more intelligibility on their own projects and mainly to manage more efficiently corporate e-Learning systems and eLearning projects. More importantly, LODM provides impartial and accurate information that can support managers on how they should apply and distribute adequately their budgets in quality improvement specific areas of their projects and the expected impact that each measures will produce (dimension level and characteristic level).

This study is however limited to a specific e-Learning project, in Portugal, although the number of students under study $(n=1317)$ and Organizations $(n=16)$ is statistically representative. The Learning Officer Decision Matrix (LODM) was developed specifically for asynchronous eLearning Project, though it can be adapted for other types of e-Learning and/or blended Learning projects. Further research with larger and more diverse typologies of e-Learning projects is required in the future to strengthen the research findings.

\section{References}

Bersin, \& Associates. (2012). Learning Leaders is now the Bersin and Associates Whatworks Awards. Retrieved from http://bersin.com/wwawards/

Brandon Hall Group. (2012). Winners of the 2012 Brandon Hall Excellence in Learning Awards. Retrieved from http://www.brandonhall.com/awards/excellence-in-learning/winners-ofthe-2012.html

Cronbach, L. J., \& Shavelson, R. J. (2004). My current thoughts on coefficient alpha and successor procedures. Educational and Psychological Measurement, 64(3), 391-418.

Fornell, C., \& Bookstein, F. L. (1982). The two structural equation models: LISREL and PLS applied to customer exit-voice theory. Journal of Marketing Research, 19, 440-452.

Gagne, R. M., Briggs, L., \& Wager, W. W. (1992). Principles of Instructional Design. Fort Worth, TX: HBJ College Publishers 
Keller, J. M. (2008). First principles of motivation to learn and e3-learning. Distance Education, 29(2), 175-185.

Levy, Y. (2006). Assessing the value of e-Learning systems. Hershey, PA: Information Science Publishing.

Levy, Y. Murph, K. \& Zanakisy (2009). A Value-Satisfaction Taxonomy of IS Effectiveness (VSTISE): A Case Study of User Satisfaction with IS and User-Perceived Value of IS. International Journal of Information Systems in the Service Sector, 1(1), 93-118.

Merrill, M. D. (2002). First principles of instruction. Educational technology research and development, 50(3), 43-59.

Merrill, M. D. (2007). First Principles of Instruction: A Synthesis. In R. A. Reiser \& J. V. Dempsey (Eds.), Trends and Issues in Instructional Design and Technology. Columbus: Ohio: Merrill Prentice Hall.

Negash, S., \& Wilcox, V. M. (2008). E-Learning Classifications: Differences and Similarities. In Negash, S., Whitman, M., Woszczynski, A., Hoganson, K., and Mattord, H. (Eds.), Distance Learning for Real-Time and Asynchronous Information Technology Education, IGI Global, Hershey: Information Science Reference.

Nisbet, R., Elder, J. \& Miner, G. (2009). Handbook of statistical analysis and data mining applications. London: Academic Press.

Sangrà, A., Vlachopoulos, D., \& Cabrera, N. (2012). Building an inclusive definition of eLearning: An approach to the conceptual framework.The International Review Of Research In Open And Distance Learning, 13(2), 145-159.

Van Merrienboer, J. J., \& Sweller, J. (2005). Cognitive load theory and complex learning: Recent developments and future directions. Educational psychology review, 17(2), 147177.

Van Merriënboer, J. J., \& Kirschner, P. A. (2012). Ten steps to complex learning: A systematic approach to four-component instructional design. Routledge.

Webster, J., \& Hackley, P. (1997). Teaching effectiveness in technology-mediated distance learning. Academy of Management Journal, 40(6), pp. 1282-1309. 


\section{Appendix A - e-Learning System Characteristics}

\begin{tabular}{|c|c|}
\hline \multicolumn{2}{|c|}{ TECHCNOLOGY AND SUPPORT DIMENSION } \\
\hline A1 & Quick answer from technical support via phone \\
\hline $\mathbf{A 2}$ & Quick answer from technical support after-hours via e-mail \\
\hline $\mathbf{A 3}$ & Quality of technical support \\
\hline A4 & System operation time (up-time) \\
\hline A5 & Reduced system errors \\
\hline A6 & System security (discourage hacking, secure access, etc.) \\
\hline A7 & Access to courses from anywhere in the world (via the Internet) \\
\hline A8 & High Network availability \& Low network congestion \\
\hline A9 & Learning at any time of the day (schedule flexibility) \\
\hline A10 & Submit assignments from anywhere (via the Internet) \\
\hline A11 & Different system tools (chat, bulletin-board or discussion forums, etc.) \\
\hline A12 & Access of all courses from one area (My LMS) \\
\hline $\mathbf{A 1 3}$ & Taking quizzes remotely (off-campus) \\
\hline A14 & Review course materials \\
\hline \multicolumn{2}{|c|}{ COURSE DIMENSION } \\
\hline B1 & Availability of course content \\
\hline B2 & Quality content of courses \\
\hline B3 & Amount of material in courses \\
\hline B4 & Interesting subject matter \\
\hline B5 & Difficulty of subject matter \\
\hline B6 & Availability of other content (syllabus, objectives, assignments, schedule) \\
\hline B7 & Enjoyment from the courses/lessons \\
\hline B8 & Ease-of-use (with course content, navigation, interface, etc.) \\
\hline B9 & Similar of interface across all online courses \\
\hline B10 & Gathering information quickly \\
\hline B11 & $\begin{array}{l}\text { Organization of courses (content of courses, organization of assignments, etc. across all course } \\
\text { modules) }\end{array}$ \\
\hline B12 & Taking practice tests prior to graded test \\
\hline \multicolumn{2}{|c|}{ LEARNER DIMENSION } \\
\hline D1 & Learning a lot in these classes \\
\hline D2 & Amount of interaction with classmates \\
\hline D3 & Quality of interaction with classmates \\
\hline
\end{tabular}




\begin{tabular}{|l|l|}
\hline D4 & Classmates' attitude (across all courses) \\
\hline D5 & Being part of a 'class' although it was online \\
\hline D6 & Your comfort with online learning and technology \\
\hline D7 & Your Internet and computer skills \\
\hline D8 & Self-discipline and time management \\
\hline D9 & Cost of courses \\
\hline D10 & Cost of ISP and Internet access \\
\hline D11 & Reduced travel cost/time (to and from campus) \\
\hline D12 & Ability to travel while taking online courses (for business or other) \\
\hline D13 & Employer support and your ability to work while learning \\
\hline D14 & Attendance to family responsibilities \\
\hline D15 & Family support \\
\hline
\end{tabular}




\section{Appendix B - Partial Least Squares: Outer Weights and Path} Coefficients

\begin{tabular}{|c|c|c|c|c|c|c|}
\hline & $\begin{array}{l}\text { Course } \\
\text { Contents }\end{array}$ & $\begin{array}{l}\text { Accessibility/ } \\
\text { Asynchronous }\end{array}$ & $\begin{array}{l}\text { Perceived } \\
\text { Value }\end{array}$ & Class & Helpdesk & Levis \\
\hline b1 & 0,0877 & & & & & 0,0343 \\
\hline $\mathrm{b} 2$ & 0,0879 & & & & & 0,0344 \\
\hline b3 & 0,0878 & & & & & 0,0343 \\
\hline $\mathrm{b} 4$ & 0,0850 & & & & & 0,0332 \\
\hline $\mathrm{b} 5$ & 0,0876 & & & & & 0,0343 \\
\hline b6 & 0,0882 & & & & & 0,0345 \\
\hline $\mathrm{b} 7$ & 0,0900 & & & & & 0,0352 \\
\hline $\mathrm{b} 8$ & 0,0886 & & & & & 0,0346 \\
\hline b9 & 0,0902 & & & & & 0,0353 \\
\hline b10 & 0,0892 & & & & & 0,0349 \\
\hline b11 & 0,0895 & & & & & 0,0350 \\
\hline b12 & 0,0833 & & & & & 0,0325 \\
\hline D1 & 0,0858 & & & & & 0,0335 \\
\hline $\mathrm{a} 4$ & & 0,1038 & & & & 0,0290 \\
\hline a5 & & 0,1048 & & & & 0,0293 \\
\hline a6 & & 0,1117 & & & & 0,0312 \\
\hline a7 & & 0,1083 & & & & 0,0303 \\
\hline a8 & & 0,1106 & & & & 0,0309 \\
\hline a9 & & 0,1069 & & & & 0,0299 \\
\hline a10 & & 0,1104 & & & & 0,0308 \\
\hline a11 & & 0,1143 & & & & 0,0319 \\
\hline a12 & & 0,1169 & & & & 0,0327 \\
\hline a13 & & 0,1128 & & & & 0,0315 \\
\hline a14 & & 0,1057 & & & & 0,0295 \\
\hline D6 & & & 0,1300 & & & 0,0348 \\
\hline D7 & & & 0,1297 & & & 0,0347 \\
\hline D8 & & & 0,1264 & & & 0,0338 \\
\hline D9 & & & 0,1078 & & & 0,0288 \\
\hline D10 & & & 0,1093 & & & 0,0292 \\
\hline D11 & & & 0,1145 & & & 0,0306 \\
\hline
\end{tabular}




\begin{tabular}{|l|l|l|l|l|l|l|}
\hline D12 & & & 0,1193 & & & 0,0319 \\
\hline D13 & & & 0,1143 & & & 0,0306 \\
\hline D14 & & & 0,1165 & & & 0,0312 \\
\hline D15 & & & 0,1118 & & & 0,0299 \\
\hline D2 & & & & 0,2594 & & 0,0277 \\
\hline D3 & & & & 0,2616 & & 0,0280 \\
\hline D4 & & & & 0,2647 & & 0,0283 \\
\hline D5 & & & & 0,2683 & & 0,0287 \\
\hline a1 & & & & & 0,3359 & 0,0260 \\
\hline a2 & & & & & 0,3543 & 0,0274 \\
\hline a3 & & & & & & 0,3725 \\
\hline
\end{tabular}

\begin{tabular}{|l|l|l|l|l|l|c|}
\hline & $\begin{array}{c}\text { Original } \\
\text { sample } \\
(\mathrm{O})\end{array}$ & $\begin{array}{c}\text { Sample } \\
\text { mean (M) }\end{array}$ & $\begin{array}{c}\text { Standard } \\
\text { Deviation } \\
(\text { STDEV) }\end{array}$ & $\begin{array}{c}\text { Standard } \\
\text { Error } \\
(\text { STERR })\end{array}$ & $\begin{array}{c}\text { Statistica } \\
1 \mathrm{~T}\end{array}$ & $\mathrm{p}$ \\
\hline $\begin{array}{l}\text { Accessibility/ } \\
\text { Asynchronous -> Levis }\end{array}$ & 0,2794 & 0,2787 & 0,0115 & 0,0115 & 24,3406 & $<0,001$ \\
\hline Course Contents -> Levis & 0,3909 & 0,3925 & 0,0165 & 0,0165 & 23,7574 & $<0,001$ \\
\hline Helpdesk -> Levis & 0,0773 & 0,0761 & 0,0062 & 0,0062 & 12,5478 & $<0,001$ \\
\hline Class -> Levis & 0,1069 & 0,1075 & 0,0086 & 0,0086 & 12,4063 & $<0,001$ \\
\hline Perceived Value -> Levis & 0,2674 & 0,2668 & 0,0123 & 0,0123 & 21,7117 & $<0,001$ \\
\hline
\end{tabular}

Path Coefficients - Correlation coefficients between factors and Dimension

\section{Author's Biography}

Nuno Pena is a Senior Learning Officer, Director of UnYLeYa (LeYa Group) and Associated Researcher at ADVANCE Research Center of ISEG - School of Economics and Management (Technical University of Lisbon). Nuno finished his Postdoc in the field of Management Information Systems, holds a Ph.D. in Information Management, a Master degree in Multimedia Educational Communication; a Postgraduate certificate in Education (PGCE) and a Bachelor in Philosophy. 